\title{
Twenty fascinating conversations
}

D

id you know we have the sequence of the human genome because of baguettes? That a child helping his mother with the laundry led to gel electrophoresis? And that one of Boston's most prominent scientists had to promise never to practice medicine as a condition of getting his MD degree?

It has been the privilege of my professional career to get to hear and transmit these stories in the series Conversations with Giants in Medicine. In the second half of this tenure of the JCI, I've had the unique opportunity to interview 20 charming and quirky scientists (Figure 1). Among this accomplished group are presidents and deans of various institutions, Nobel and Lasker laureates, and those behind blockbuster pharmaceuticals. And because these individuals are never unidimensional, among this cohort are musicians, a pilot, and a member of the basketball hall of fame.

In the video that accompanies this piece (www.jci.org/videos/cgms), I've highlighted several of my favorite moments from this second half of the Conversations series. You'll hear about how David Nathan was ordered to become a hematologist by a captain in the Navy, how Helen Hobbs almost ended up as a cruise ship doctor, how Laurie Glimcher left medical school in tears after her first day, and also how Sasha Rudensky's passport ended up in the hands of the CIA.

Behind these towering giants and scientific Goliaths are real people, with entertaining stories and sometimes strange senses of humor. In common among them all: dogged persistence and a passion for scientific discovery. One of the questions I've asked all subjects is whether they would ever choose another profession; the one unifying thing among these diverse scientists is that most have said they could never envision another path. Their love of science is intense.

I tip my hat to Howard Rockman for having the original idea for these conversations, to Francesco Rulli for being
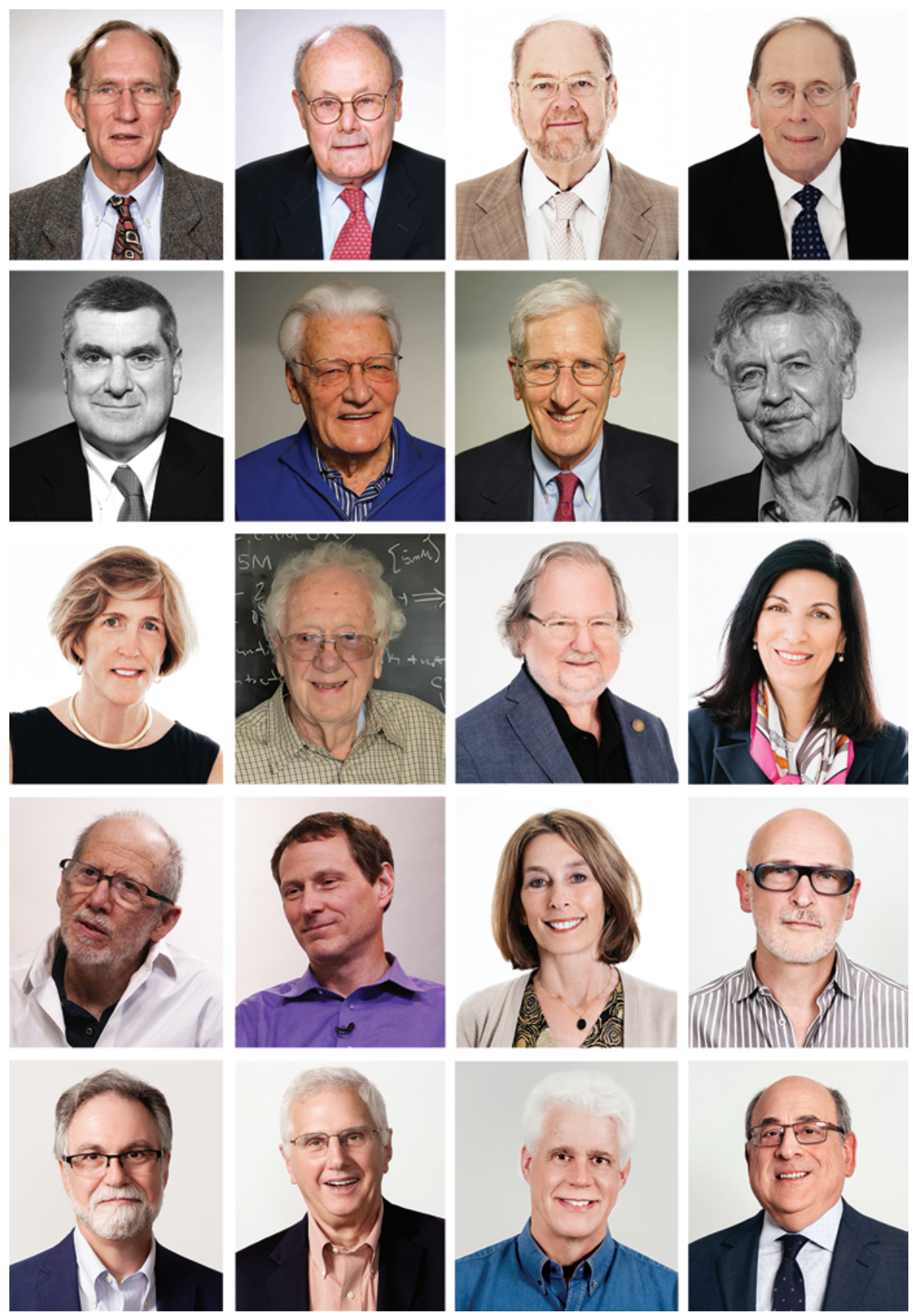

Figure 1. Scientists recently interviewed for the series Conversations with Giants in Medicine. Top row: Peter Agre, David Nathan, James Rothman, William Paul. Second row: Craig Thompson, Robert Schrier, Stuart Kornfeld, Rudolf Jaenisch. Third row: Helen Hobbs, Oliver Smithies, James Allison, Huda Zoghbi. Fourth row: Bert Vogelstein, Kenneth Kinzler, Laurie Glimcher, Alexander Rudensky. Bottom row: Gregg Semenza, Bruce Alberts, Eric Olson, Stuart Orkin.

the first producer of the series, and to the incomparable videographers and editors extraordinaire Semyon Maltsev and
Alexey Levchenko of Image Media Lab. I hope to continue more Conversations in the years to come, and as always, I welcome your feedback. 